\title{
Cloning and expression analysis of heat shock cognate 70 gene promoter in tiger shrimp (Penaeus monodon)
}

\author{
Kuo-Hung Chuang ${ }^{\text {a, }}$, Shih-Hu Ho ${ }^{\text {a, } 1}$, Yen-Ling Song ${ }^{\text {a,b,* }}$ \\ a Institute of Zoology, National Taiwan University, Taipei, Taiwan, ROC \\ ${ }^{\mathrm{b}}$ Department of Life Science, National Taiwan University, Taipei, Taiwan, ROC
}

Received 19 March 2007; received in revised form 4 July 2007; accepted 10 August 2007

Available online 5 September 2007

Received by A.J. van Wijnen

\begin{abstract}
Heat shock cognate 70 (HSC70) functions as a molecular chaperon and plays an important role in protein folding. HSC70 cDNA of tiger shrimp (Penaeus monodon) was cloned and characterized in our previous study. After shrimps were treated with the 1-hr heat shock, the HSC70 mRNA level in hemocytes increased ( $\sim 8$ fold) using real-time quantitative PCR. An hsc70 clone was obtained from genomic library screening. The gene contains 2 exons separated by a 1557-bp intron. The $5^{\prime}$-flanking region sequence $(\sim 1 \mathrm{~kb})$ ahead of the $h s c 70 \mathrm{gene}$ contains a putative core promoter region and transcription elements including perfect heat shock element (HSE), imperfect HSE, CAAT elements, SP1, NF$\mathrm{kB}$ and GC box. In insect $S f 21$ cells, the region could drive expression of the enhanced green fluorescent protein (EGFP) and luciferase gene to verify its promoter function. In the luciferase assay system, the effects of serial deletions on the hsc70 promoter were elucidated. Autographa californica multiple nuclear polyhedrosis virus infection $(\mathrm{MOI}=0.1)$ on $S f 21$ cells significantly increased the $h s c 70$ promoter activity. In addition, the effects of amino acid analogs and arsenic acid incubation with the cells on the $h s c 70$ promoter activity were examined.
\end{abstract}

(C) 2007 Elsevier B.V. All rights reserved.

Keywords: Promoter activity; Gene regulation; Virus infection

\section{Introduction}

Heat shock protein 70 (HSP70) is found in diverse organisms from bacteria to mammals. It plays an important role in the synthesis of proteins in a normal cellular condition, fixing denatured proteins and preventing the misfolding or aggregation of proteins (Hartl, 1996; Bukau and Horwich, 1998; Bukau et al., 2000). The expression can be induced by a hundred-fold compared to the normal condition in which the heat shock

Abbreviations: HSC70 (hsc70), heat shock cognate 70; HSE, heat shock element; Sf21, Spodoptera frugiperda Sf21 cell line; EGFP, enhanced green fluorescent protein; FCS, fetal calf serum; AcMNPV, Autographa californica multiple nuclear polyhedrosis virus; MOI, multiplicity of infection; ANOVA, analysis of variance.

* Corresponding author. Institute of Zoology, National Taiwan University, No. 1, Sec. 4, Roosevelt Road, Taipei 10617, Taiwan. Tel.: +886 23366 2455; fax: +886223660243.

E-mail address: song@ntu.edu.tw (Y.-L. Song).

${ }^{1}$ These authors equally contributed to the present study. protein is expressed at very low level. Usually, there is no intron in $h s p 70$ gene structure. In contrast, heat shock cognate 70 (HSC70) has a constitutive expression and functions as a molecular chaperon. At best, the expression can be induced by only several folds. There are usually introns in $h s c 70$ gene structure.

In addition to heat shock, the expression of HSP70 has also been reported to be induced under various stress conditions such as pathogen infection, amino acid analog (Mosser et al., 1988; Williams and Morimoto, 1990), heavy metal ions (Mosser et al., 1988; Yamuna et al., 2000; Boone and Vijayan, 2002), hypoxic condition (Cheng et al., 2003) and osmotic stress (Spees et al., 2002). Adenovirus ElA product can activate $h s p 70$ promoter (Kraus et al., 1992) and baculovirus infection can also activate the Drosophila heat shock 70 promoter (Crouch and Passarelli, 2005).

In shrimps, a few molecular cloning of HSP70 and HSC70 has been done. HSC70 cDNA of tiger shrimp (P. monodon) was cloned and characterized (Lo et al., 2004). HSP70 and HSC70 
cDNA were cloned from giant freshwater prawn Macrobachium rosenbergii (Liu et al., 2004). Besides, a Litopenaeus vannamei HSP70 gene sequence (Genbank accession no. AY645906) and a Fenneropenaeus chinensis HSC70 cDNA sequence (Genbank accession no. AY748350) were submitted to Genbank. However, there is no report yet on the study of gene promoter in shrimp HSP70 or HSC70.

P. monodon is an important economic aquaculture shrimp species in Taiwan and Southeastern Asia. The HSC70 of $P$. monodon is constitutively expressed in most tissues of shrimp. After a heat shock stimulation, the mRNA level in hemocytes increases 2- to 3- fold (Lo et al., 2004). For more understanding of the $h s c 70$ gene regulation and further possible application, the $h s c 70$ promoter from P. monodon was cloned in this study. The promoter activity was analyzed in heterogeneous cell culture system. The induction conditions of the promoter including virus infection, amino acid analogs and heavy metal ion arsenic were also tested.

\section{Materials and methods}

\subsection{Determination of HSC70 mRNA expression in hemocytes after heat shock}

Experimental shrimps were maintained at $26 \pm 1{ }^{\circ} \mathrm{C}$ for 2 weeks before heat shock treatment. Three shrimps were then transferred to the tank at $36 \pm 1{ }^{\circ} \mathrm{C}$ (heat shock) or $26 \pm 1{ }^{\circ} \mathrm{C}$ (mock) respectively, and three shrimps remained in the same tank (untreated). After one hour of incubation, shrimp hemolymph was drawn with anticoagulant (sodium citrate $0.1 \mathrm{M}$, sucrose $0.4 \mathrm{M}$, Tris- $\mathrm{HCl} 0.01 \mathrm{M}, \mathrm{pH} 7.6$, osmolarity was adjusted to $780 \mathrm{mOsm} / \mathrm{kg}$ ) and centrifuged at $300 \times g, 4{ }^{\circ} \mathrm{C}$. Total RNA sample was extracted from hemocytes of individual shrimp using Trizol reagent (Invitrogen) according to the manufacturer's instructions and cDNA was synthesized using THERMOSCRIPT ${ }^{\mathrm{TM}}$ reverse transcriptase (Invitrogen).

Real-time quantitative PCR was carried out to measure the level of $h s c 70$ mRNA using forward primer $5^{\prime}$-TGTCGGTATTGATCTGGGAA-3' and reverse primer 5'-ACGCTCTGTGTCTGTGAAGG-3' based on the HSC70 cDNA (Lo et al., 2004). Actin as internal control was detected with forward primer 5'-GCGACGTGGACATCCGTAA-3' and reverse primer 5'CGATGCCAGGGTACATGGTAGT-3'. The hemocyte cDNA, primer pairs, and $\mathrm{iQ}^{\mathrm{TM}} 2 \mathrm{X}$ SYBR Green Supermix (Bio-Rad) were reacted and detected with an iCycler iQ Multicolor Realtime PCR Detection System (Bio-Rad). The thermal cycling parameters were $3 \mathrm{~min}$ at $94^{\circ} \mathrm{C}$, and 40 cycles run for $30 \mathrm{sec}$ at $95{ }^{\circ} \mathrm{C}$ and $1 \mathrm{~min}$ at $60^{\circ} \mathrm{C}$. The specificity of PCR products was confirmed by melting curve analysis.

\subsection{Isolation of hsc70 promoter from tiger shrimp genomic library}

A tiger shrimp genomic library shf01, which had been constructed in the vector CopyControl ${ }^{\mathrm{TM}}$ pCC1FOS $^{\mathrm{TM}}$ fosmid (Epicentre) using DNA extracted from muscle, and maintained in E. coli strain EPI300-T1 ${ }^{\mathrm{R}}$ (Epicentre), was purchased from Food Industry Research and Development Institute, Taiwan.
To prepare a probe suitable for selection and cloning of the $h s c 70$ gene, a DIG-labeled $h s c 70$-specific 436 -bp probe was amplified by PCR on the cDNA clone (Lo et al., 2004) using 5'GTACCGGCKTATTTYAACGA-3' as the forward primer and 5'-TACCTTCGAAGAGGGAGTCG-3' primer as the reverse primer. Thirty cycles were used, consisting of $30 \mathrm{~s}$ at $94^{\circ} \mathrm{C}, 30 \mathrm{~s}$ at $55^{\circ} \mathrm{C}$ and $45 \mathrm{~s}$ at $72{ }^{\circ} \mathrm{C}$, and using DIG DNA labeling Mix (Roche) as dNTP substrate.

The library colonies were transferred to Hibond-N+ membranes (Amersham) and lysis were carried out, followed by UVcrosslinking of the blotted membrane according to the manufacturer's instructions. After hybridization at $42{ }^{\circ} \mathrm{C}$ overnight, the membrane was washed twice with $2 \times \mathrm{SSC}, 0.1 \% \mathrm{SDS}$ at room temperature and twice with $0.1 \times \mathrm{SSC}, 0.1 \% \mathrm{SDS}$ at $68{ }^{\circ} \mathrm{C}$. Then the target colony on the membrane was detected using DIG Nucleic Acid Detection Kit (Roche) and CSPD chemiluminescent substrates (Applied Biosystems) exposed to BioMax MS Film (Kodak).

The single positive clone was incubated and treated with CopyControl ${ }^{\mathrm{TM}}$ Induction Solution (Epicentre) to induce clone copy-number. The fosmid was isolated according to midipreparation method (Sambrook and Russell, 2001) and the sequence was determined (Mission Biotech, Taiwan) from coding region to $5^{\prime}$ flanking sequence.

\subsection{Sequencing for poly $C$ sequence}

Because there is a poly $\mathrm{C}$ sequence on the $5^{\prime}$ upstream of the hsc70 gene, direct sequencing on the fosmid was difficult. The fosmid was digested by PstI then a $3-\mathrm{kb}$ fragment from the fosmid was hybridized with the cDNA-specific probe. The fragment was ligated to pGEM-T Easy vector (Promega) and subsequently introduced to $E$. coli DH-5 $\alpha$ to amplify for sequencing.

\subsection{Analysis of nucleotide sequence}

The sequence was analyzed for potential promoter and transcription factor binding sites using Neural Network Promoter Prediction (http://www.fruitfly.org/seq_tools/promoter.html) (Reese, 2001) and Transcription Element Search Software (TESS) (http://www.cbil.upenn.edu/cgi-bin/tess/tess).

\subsection{Construction and transfection of EGFP plasmids}

The 5'-upstream region of the $h s c 70$ gene was amplified using PCR with primers containing recognition sites for Xma I in the forward primer 5-CCCGGGTATGCAATACTGTCAAGGAC-3' and Xho I in the reverse primer 5-CTCGAGAATAGGTTATTGGCTTACCT-3'. The product was ligated into pGEM-T Easy vector (Promega) and then subcloned into the Sac I/Sac II site of pEGFP-1 vector (Clontech).

Insect Spodoptera frugiperda Sf21 cells were routinely cultured in TNM-FH medium supplemented with $8 \%$ fetal calf serum (FCS) and grown at $26^{\circ} \mathrm{C}$. Plasmids for transfection were prepared using a purification EasyPure plasmid DNA miniprep kit (Bioman, Taiwan). Transfection experiments were performed in 12-well culture plates. Briefly, one hour before transfection, 
Table 1

The primers used in the present study

\begin{tabular}{|c|c|c|c|c|c|}
\hline No. & Sequence $\left(5^{\prime} \rightarrow 3^{\prime}\right)$ & $\begin{array}{l}\text { Position in } \\
h s c 70\end{array}$ & Usage & $\begin{array}{l}\text { Forward or } \\
\text { reverse }\end{array}$ & Enzyme \\
\hline 1 & GTACCGGC(G/T)TATTT(C/T)AACGA & $436-455$ & Preparation of the probe for screening genomic DNA library & $\mathrm{F}$ & \\
\hline 2 & TACCTTCGAAGAGGGAGTCG & $871-852$ & Preparation of the probe for screening genomic DNA library & $\mathrm{R}$ & \\
\hline 3 & TGTCGGTATTGATCTGGGAA & $18-37$ & Real-time Quantitative PCR for $h s c 70$ & $\mathrm{~F}$ & \\
\hline 4 & ACGCTCTGTGTCTGTGAAGG & $147-128$ & Real-time Quantitative PCR for $h s c 70$ & $\mathrm{R}$ & \\
\hline 5 & GCGACGTGGACATCCGTAA & & Real-time Quantitative PCR for actin & $\mathrm{F}$ & \\
\hline 6 & CGATGCCAGGGTACATGGTAGT & & Real-time Quantitative PCR for actin & $\mathrm{R}$ & \\
\hline 7 & CCCGGGTATGCAATACTGTCAAGGAC & $\begin{array}{l}-2644 \text { to } \\
-2625\end{array}$ & $\begin{array}{l}\text { Construction of full-length promoter pPmhsc70-EGFP or } \\
\text { pPmhsc70-GL3 }\end{array}$ & $\mathrm{F}$ & Xma I \\
\hline 8 & CTCGAGAATAGGTTATTGGCTTACCT & $\begin{array}{l}-1545 \text { to } \\
-1564\end{array}$ & $\begin{array}{l}\text { Construction of full-length promoter pPmhsc70-EGFP or } \\
\text { pPmhsc70-GL3 }\end{array}$ & $\mathrm{R}$ & Xho I \\
\hline 9 & GAGCTCGGATCATGATGATAAACAAT & & Construction of pOpIE2-hRL & $\mathrm{F}$ & Sac I \\
\hline 10 & $\overline{C C C G G G \text { TAAATTCGAACAGATGCTGT }}$ & & Construction of pOpIE2-hRL & $\mathrm{R}$ & $X m a \mathrm{I}$ \\
\hline 11 & GAGCTCCAAAGACATATTTCAACACA & $\begin{array}{l}-2537 \text { to } \\
-2518\end{array}$ & $\begin{array}{l}\text { Construction of pPmhsc } 70 \Delta 1-G L 3(-1545 \text { to }-2537) \text { in serial } \\
\text { deletion }\end{array}$ & $\mathrm{F}$ & Sac I \\
\hline 12 & GAGCTCATTCACGCTTCCGTCATAATG & $\begin{array}{l}-2317 \text { to } \\
-2297\end{array}$ & $\begin{array}{l}\text { Construction of pPmhsc } 70 \Delta 2-G L 3(-1545 \text { to }-2317) \text { in serial } \\
\text { deletion }\end{array}$ & $\mathrm{F}$ & Sac I \\
\hline 13 & GAGCTCACATAATAACTTTAACGTTA & $\begin{array}{l}-2160 \text { to } \\
-2141\end{array}$ & $\begin{array}{l}\text { Construction of pPmhsc } 70 \Delta 3-G L 3(-1545 \text { to }-2160) \text { in serial } \\
\text { deletion }\end{array}$ & $\mathrm{F}$ & Sac I \\
\hline 14 & $\underline{G A G C T C A A G A A C G T T T C A C T T A C C A C ~}$ & $\begin{array}{l}-1799 \text { to } \\
-1780\end{array}$ & $\begin{array}{l}\text { Construction of pPmhsc } 70 \Delta 5-G L 3(-1545 \text { to }-1799) \text { in serial } \\
\text { deletion }\end{array}$ & $\mathrm{F}$ & Sac I \\
\hline 15 & CTCGAGAATAGGTTATTGGCTTACCT & $\begin{array}{l}-1545 \text { to } \\
-1564\end{array}$ & Construction of pGL3-vectors in serial deletion & $\mathrm{R}$ & Xho I \\
\hline 16 & GAGCTCTATGCAATACTGTCAAGGAC & $\begin{array}{l}-2644 \text { to } \\
-2625\end{array}$ & Construction of pGL3-vectors in serial deletion & $\mathrm{F}$ & Sac I \\
\hline 17 & $\underline{C T C G A G G T G G T A A G T G A A A C G T T C T T}$ & $\begin{array}{l}-1780 \text { to } \\
-1799\end{array}$ & $\begin{array}{l}\text { Construction of pPmhsc } 70 \Delta 5 \text { r-GL3 }(-1780 \text { to }-2644) \text { in serial } \\
\text { deletion }\end{array}$ & $\mathrm{R}$ & Xho I \\
\hline
\end{tabular}

Note: Underline indicates restriction enzyme recognition site; the position of translation start site ATG is defined as +1 .

recipient cells were seeded into wells at a density of $4 \times 10^{5}$ cells/ well. After removal of culture medium and single wash using fresh medium without FCS, the cells were transfected with $1 \mu \mathrm{g}$ of reporter construct DNA in $500 \mu \mathrm{L}$ medium without FCS per well using $5 \mu \mathrm{L}$ Lipofectin (Invitrogen) according to the manufacturer's recommendations. At $10 \mathrm{~h}$ post transfection, the transfection mixture was replaced with the medium with $8 \%$ FCS. At $48 \mathrm{~h}$ post transfection, EGFP (enhanced green fluorescent protein) expression was observed using an inverted fluorescence microscope.

\subsection{Construction, transfection and activity assay of luciferase plasmids}

The 5'-upstream region and its serial-deleted fragments of the $h s c 70$ gene were amplified using PCR with primers listed in Table 1. The product was ligated into pGEM-T Easy vector (Promega) and then subcloned into the SacI/XhoI site of pGL3Basic vector (Promega). A schematic drawing of the reporter constructs is shown in Fig. 4.

The luciferase assay was performed using Dual-Glo luciferase assay system (Promega) with pOpIE2-hRL vector (Renilla luciferase gene driven by Orgyia pseudotsugata immediate early promoter) as an internal control for normalization of transfection efficiency. Transfection experiments were performed in 24-well cell culture plates. Briefly, one hour before transfection, recipient $S f 21$ cells were seeded at a density of $2 \times 10^{5}$ cells/well. After removal of culture medium and single wash using fresh medium without FCS, the cells were cotransfected with $1 \mu \mathrm{g}$ of firefly luciferase reporter construct DNA and $0.1 \mu \mathrm{g}$ of control plasmid (pOpIE2-hRL) per well using $35 \mu \mathrm{L}$ Cellfectin Transfection Reagent (Invitrogen) with $200 \mu \mathrm{L}$ medium without FCS according to the manufacturer's recommendations. At $10 \mathrm{~h}$ post transfection, the transfection mixture was replaced with the medium with $8 \%$ FCS. Cells were harvested at $72 \mathrm{~h}$ post transfection, firefly and Renilla luciferase activity was measured by the Dual-Glo luciferase assay system according to the manufacturer's instructions and chemiluminescence was read by a Luoroskan Ascent FL

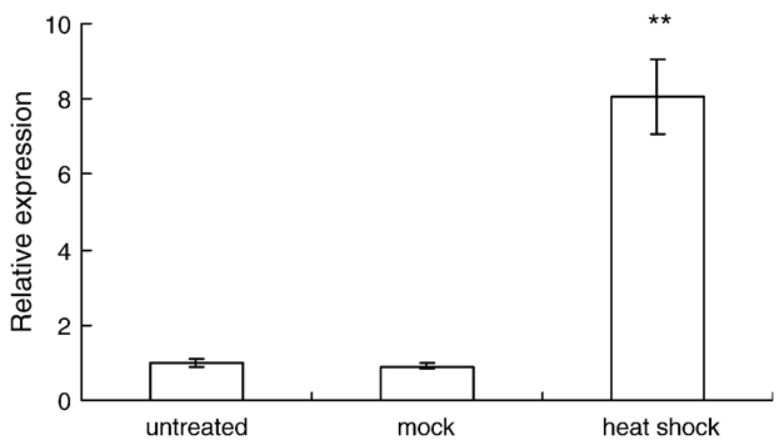

Fig. 1. The HSC70 mRNA relative expression estimated by real-time quantitative PCR in hemocytes of tiger shrimps $(n=3)$ treated with heat shock $\left(26 \pm 1{ }^{\circ} \mathrm{C} \rightarrow 36 \pm 1{ }^{\circ} \mathrm{C}\right)$ for $1 \mathrm{hr}$. The error bar represents \pm 1 standard error. The treatments affected the relative expression significantly (ANOVA, $p<0.01$ ). The $* *$ indicates significant difference compared with the untreated and mock group (Scheffe method, $p<0.01$ ). 
(Labsystems) reader. The co-expressed Renilla luminescence was used to normalize the firefly luminescence.

\subsection{Effect of virus infection on the hsc70 promoter}

At $10 \mathrm{hr}$ post transfection of the luciferase plasmids, the cells were infected by DsRed-introduced AcMNPV (Autographa californica multiple nuclear polyhedrosis virus) with MOI (multiplicity of infection) $0.1,0.01,0.001$ or 0.0001 . At $48 \mathrm{hr}$ after virus infection, the DsRed fluorescence which expresses infection of the virus was observed. At $72 \mathrm{~h}$ post infection, the luciferase activity was measured as previously described.

\subsection{Effect of amino acid analogs on the hsc70 promoter}

After transfection of the luciferase plasmids, the cells were incubated in TNM-FH medium (with $8 \%$ FCS) with 5,10 or $20 \mathrm{mM}$ amino acid analog azetidine (Sigma) for 7, 12 or $24 \mathrm{~h}$. Then the medium was replaced with fresh medium without amino acid analog. At $72 \mathrm{~h}$ post transfection, the luciferase

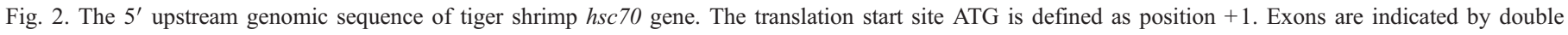

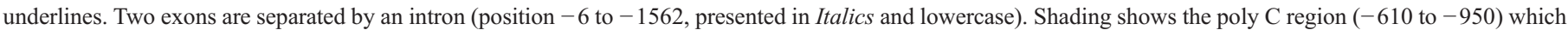

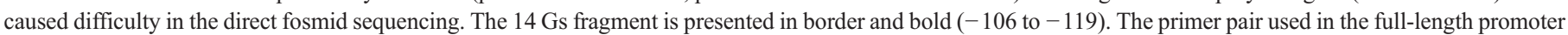
cloning is indicated by arrows. The putative promoter and transcriptional factor binding elements are shown with indicated names. 


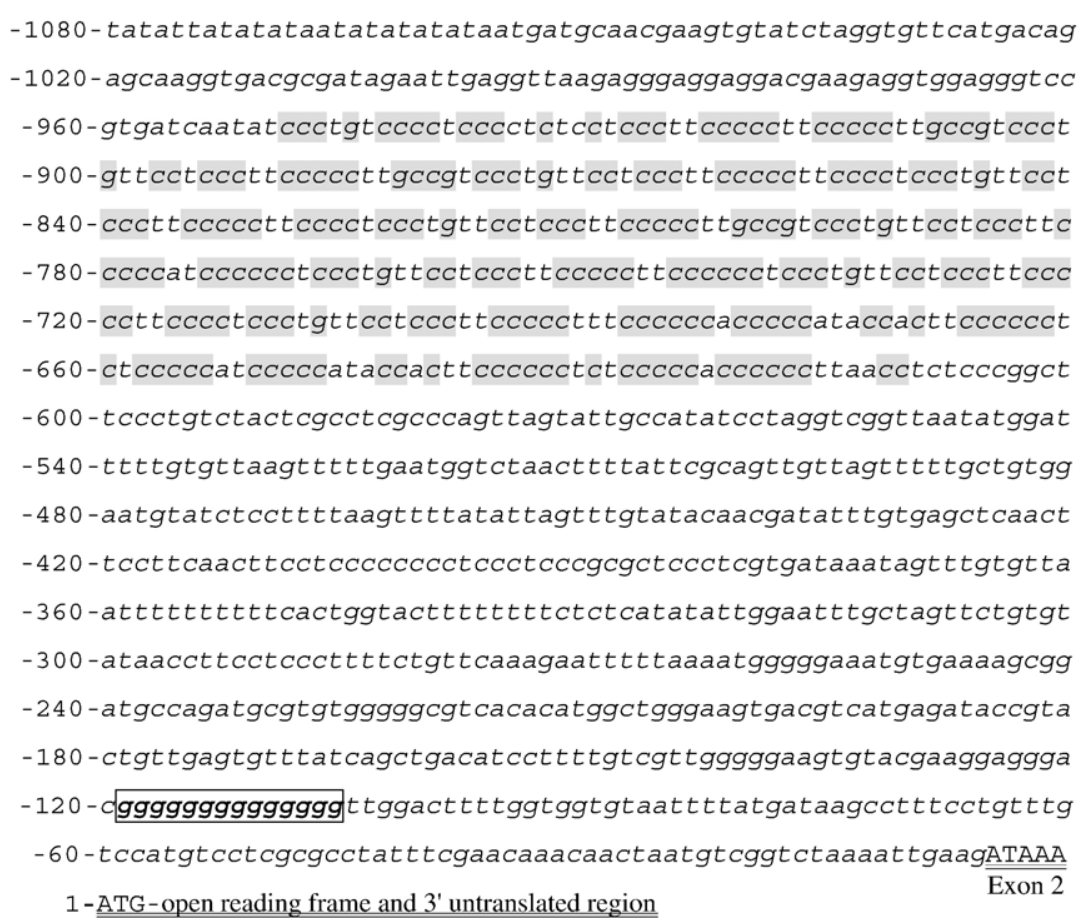

Fig. 2 (continued). activity was measured as described earlier. Another amino acid analog L-canavanine (Sigma) was also tested in the same way but for a duration of 1 or $4 \mathrm{~h}$ of incubation.

\subsection{Effect of arsenic acid on the hsc70 promoter}

After transfection of the luciferase plasmids, the cells were incubated in TNM-FH medium (with $8 \%$ FCS) with 400,800 or $1200 \mu \mathrm{M} \mathrm{Na}_{2} \mathrm{HAsO}_{4}$ (Sigma) for 3 or $6 \mathrm{~h}$. Then the medium was replaced with fresh medium without arsenic acid. At $72 \mathrm{~h}$ post transfection, the luciferase activity was measured as described earlier.

\section{Results}

\subsection{Expression of HSC70 mRNA in hemocytes after heat shock}

The HSC70 mRNA level was estimated using reverse transcription and real-time quantitative PCR. The HSC70 mRNA relative expression of the shrimps treated with the 1-hour heat shock is higher ( $\sim 8$ fold) than the mock and the untreated groups (Fig. 1). There is no significant difference between the mock and the untreated groups.

\subsection{Complete hsc70 gene and 5' upstream sequence}

A 5329-bp sequence (GenBank accession no. EF472918) was obtained from a positive fosmid clone from the library screening. It contains the complete genomic sequence of the $h s c 70$ gene and the $5^{\prime}$-flanking region. The shrimp $h s c 70$ gene contains 2 exons ( $\sim 59$ bp and 2412 bp) separated by a 1557-bp intron, complying with the canonical GT/AG splicing recognition rule at the extreme ends of the intron (Fig. 2). The identity between the exons in the present study and the cDNA sequence reported by Lo et al. (2004) reaches $99 \%$.

The 5 '-flanking sequence (1301 bp) ahead of the $h s c 70$ gene contains a putative core promoter region (1692-1644 bp ahead of start codon ATG) (Fig. 2). Transcription factor binding elements were predicted including 1 perfect heat shock element (HSE), 1 imperfect HSE, 6 CAAT elements, 1 SP1, 1 NF- $\kappa \mathrm{B}$ and $1 \mathrm{GC}$ box. In addition, there is a fragment containing 14 deoxyguanylates (Gs) (119 bp ahead of start codon ATG) and a poly C region (610-950 ahead of start codon ATG) which caused difficulty in the direct fosmid sequencing.

\subsection{Activity of hsc70 promoter in vitro}

To identify the promoter function, the $5^{\prime}$-upstream region (2644-1545 bp ahead of start codon ATG) of the hsc70 gene was inserted into pEGFP-1 vector and used to drive expression of the EGFP gene in $S f 21$ cells. EGFP fluorescent signals were observed (Fig. 3).

A series of different spans of the possible promoter and transcriptional factor binding element region was inserted into pGL3-Basic vector respectively and used to drive expression of the luciferase gene in $S f 21$ cells (Fig. 4). The full-length promoter (2644-1545 bp ahead of start codon ATG) generated a $\sim 15$-fold increase in luciferase expression relative to the promoter-less vector (pGL3-Basic). Deletion of 2644 to 2538, 2318 and $2161 \mathrm{bp}$ ahead of translation start codon ATG could not significantly affect the promoter activity. Further deletion to position -1800 which removed the predicted GC box, NF-kB and CCAAT sites decreased the expression to a significantly low level. The fragment containing only $2644-1780 \mathrm{bp}$ ahead 

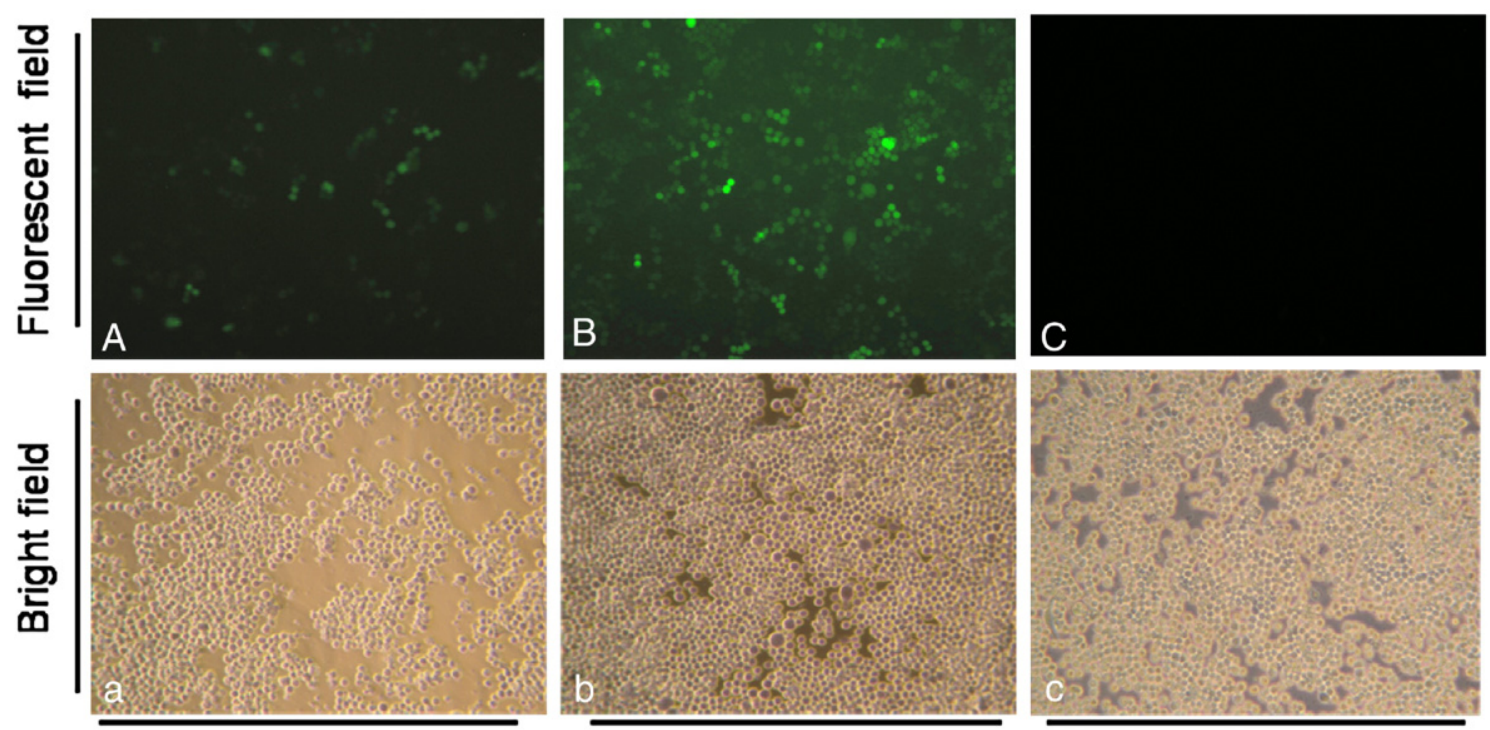

pPmhsc70-EGFP

pCMV-pEGFP

pEGFP-1

Fig. 3. EGFP expression of the tiger shrimp $h s c 70$ promoter in $S f 21$ cells at $48 \mathrm{~h}$ post transfection with pPmhsc70-EGFP which used the $h s c 70$ full-length promoter (A), pCMV-EGFP which used CMV promoter as a positive control (B) and promoter-less pEGFP-1 as a negative control (C). Bright fields are shown in lower row, respectively $(\mathrm{a}-\mathrm{c})$.

of start codon ATG without the predicted core promoter region, the perfect HSE and a CCAAT site has significantly lower activity than the full-length promoter.

\subsection{Effect of virus infection on hsc70 promoter}

The variable MOI of AcMNPV infection significantly affected the relative luciferase expression of the $h s c 70$ promoter
(ANOVA, $\mathrm{p}<0.05$; Fig. 5). High-dose AcMNPV infection $(\mathrm{MOI}=0.1)$ significantly increased the $h s c 70$ promoter activity.

\subsection{Effect of amino acid analogs and arsenic acid on hsc70 promoter}

Neither canavanine nor azetidine affected the relative luciferase expression of the $h s c 70$ promoter using two-factor

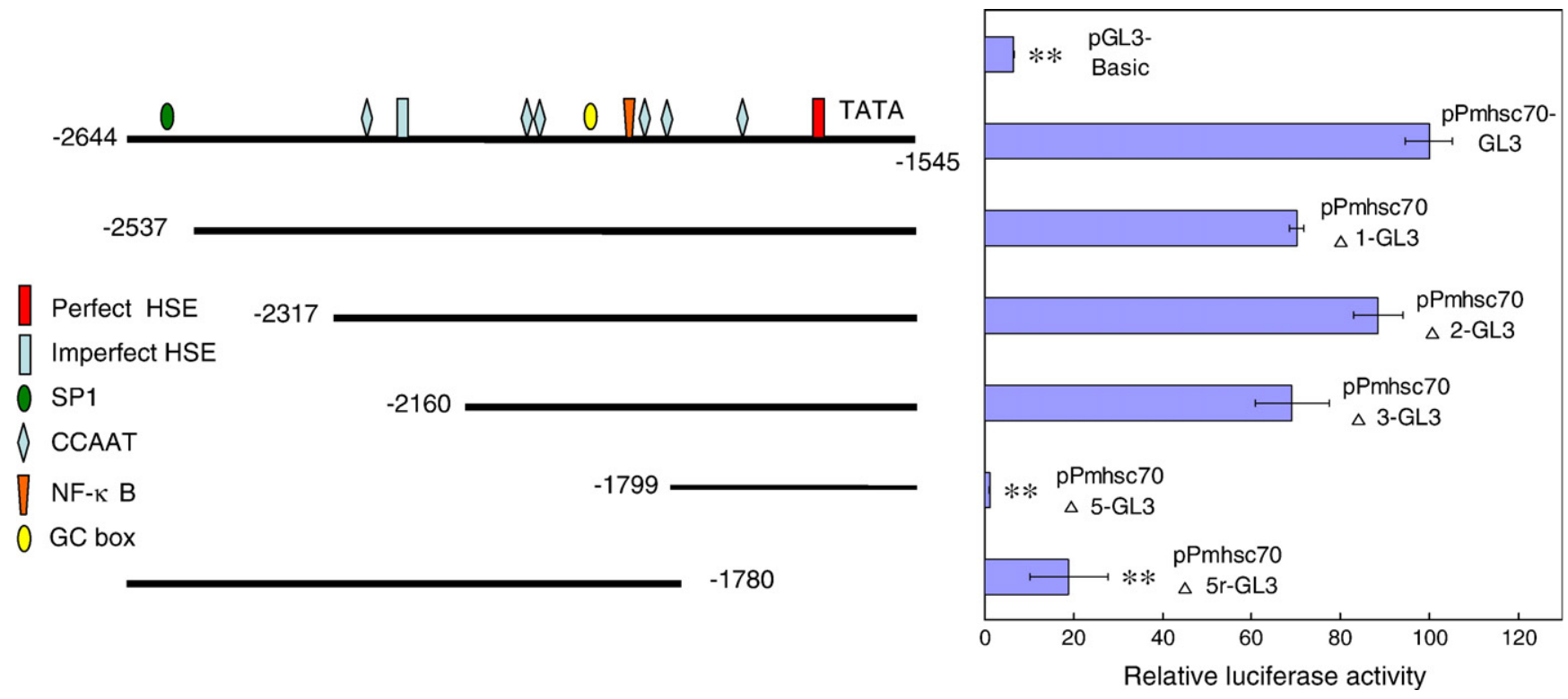

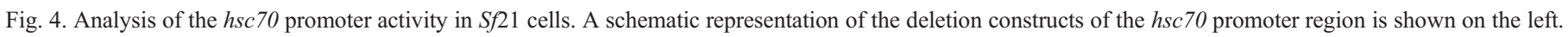

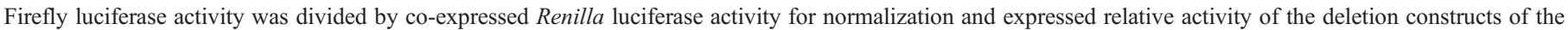

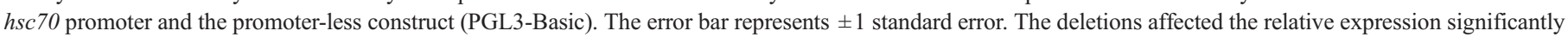

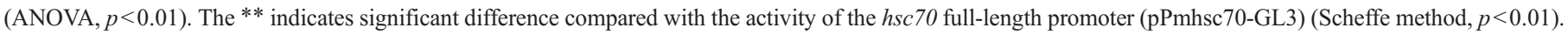




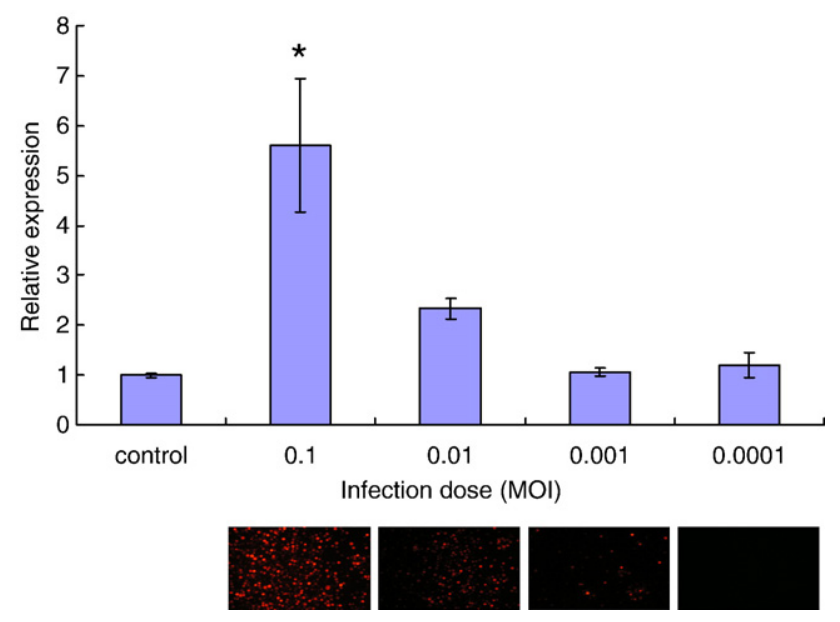

Fig. 5. The luciferase assay of the $h s c 70$ promoter in $S f 21$ cells at $72 \mathrm{~h}$ post AcMNPV infection with different MOIs. The lower fluorescent pictures were taken at $48 \mathrm{~h}$ after the infection with the indicated MOIs. The error bar represents \pm 1 standard error. The MOI treatments affected the relative expression significantly (ANOVA, $p<0.05$ ). The ${ }^{*}$ indicates significant difference compared with the control (without infection) (Scheffe method, $p<0.05$ ).

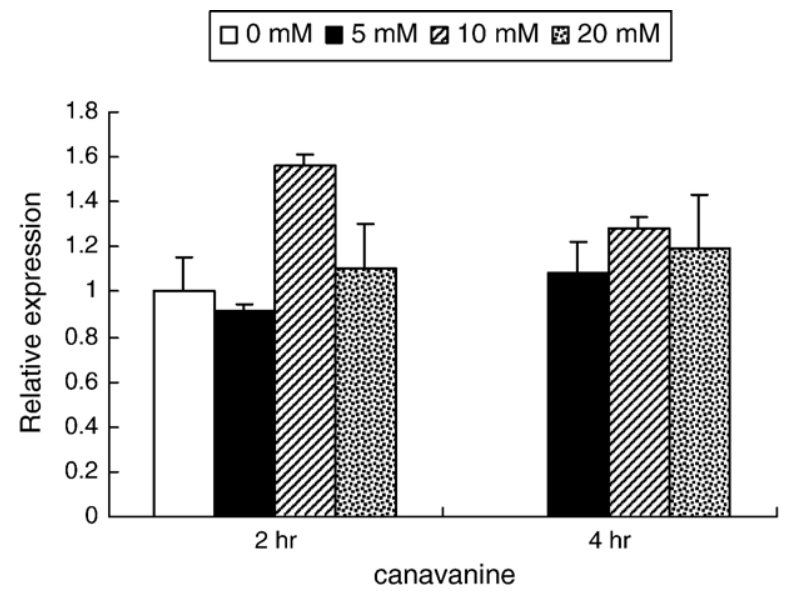

$\square 0 \mathrm{mM} \square 5 \mathrm{mM} \approx 10 \mathrm{mM}$ 田 $20 \mathrm{mM}$

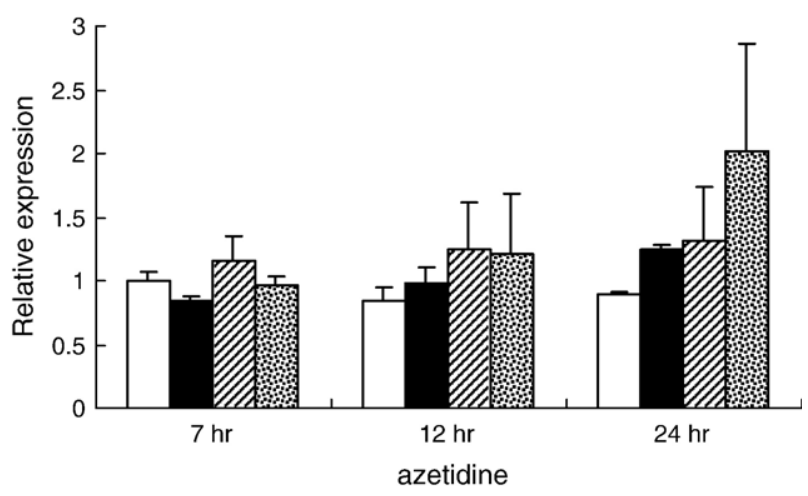

Fig. 6. The luciferase assay of the $h s c 70$ promoter in $S f 21$ cells incubated with different concentrations of amino acid analogs canavanine or azetidine and indicated incubation time. The luciferase activity was measured at $72 \mathrm{~h}$ post transfection. The error bar represents standard error. Neither canavanine nor azetidine affected the relative luciferase expression (two-factor ANOVA, $\alpha=0.05$ ).

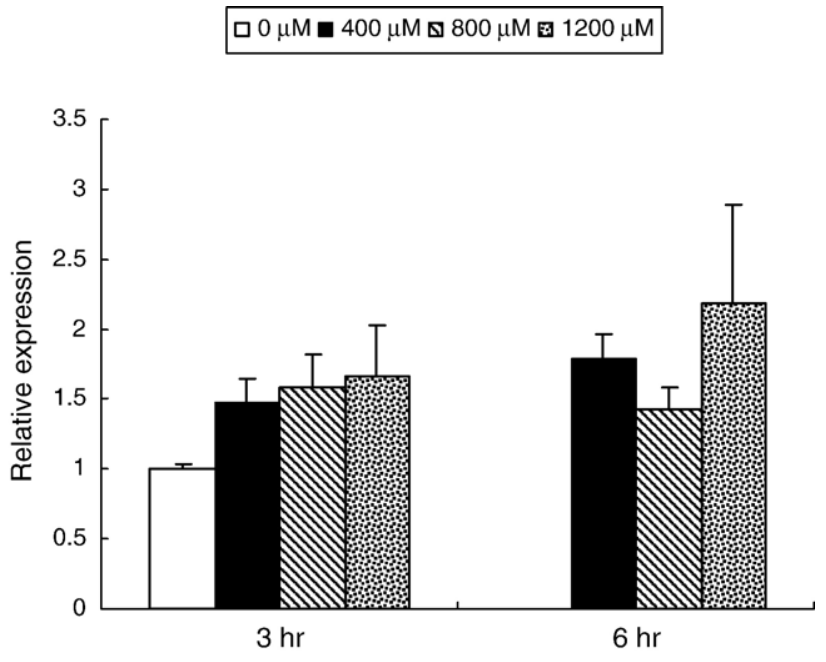

Fig. 7. The luciferase assay of the $h s c 70$ promoter in $S f 21$ cells incubated with different concentrations of arsenic acid for 3 or $6 \mathrm{~h}$. The luciferase activity was measured at $72 \mathrm{~h}$ post transfection. The error bar represents standard error. The effect of arsenic acid was not significant (two-factor ANOVA, $\alpha=0.05$ ).

ANOVA $(\alpha=0.05)$ even though the high dose seemed to increase the expression in the azetidine-treatment for $24 \mathrm{~h}$ (Fig. 6).

Arsenic acid could not affect the relative luciferase expression of the $h s c 70$ promoter using two-factor ANOVA $(\alpha=0.05)$ even though incubation with arsenic acid seemed to elevate the $h s c 70$ promoter activity rather than control $(0 \mu \mathrm{M})$ (Fig. 7).

\section{Discussion}

\subsection{HSC70 mRNA increased after a heat shock}

According to the estimation using real-time quantitative PCR, the HSC70 mRNA expression in hemocytes was induced after the heat shock by about 8 folds. (Fig. 1). Similarly, 2-3 fold induction was detected using Northern blot (Lo et al., 2004). These two results consistently indicate that the HSC70 of tiger shrimp can be induced by several folds after a heat shock. In freshwater giant prawn M. rosenbergii, Mar-HSC70 mRNA expression remains unchanged or slightly increases after a heat shock $\left(25 \rightarrow 35^{\circ} \mathrm{C}\right)$ in thoracic ganglia, hepatopancreas, ovary, gill and gut except muscle, which has a significantly increase (Liu et al., 2004). It is difficult to compare HSC70 inducibility between tiger shrimp and freshwater giant prawn due to the data from different tissues, but these results help us to get a general pattern of HSC70 expression in shrimp body in responses to heat shock stress.

\subsection{The hsc70 gene structure and the $5^{\prime}$ upstream sequence}

There are 8 introns in the $h s c 70$ of human (Dworniczak and Mirault, 1987), mouse (Giebel et al., 1988), rainbow trout (Zafarullah et al., 1992) and teleost Rivulus marmoratus (Park et al., 2001). However, there is only one intron in the $h s c 70$ of tiger shrimp as in fruit fly (Perkins et al., 1990). But there are 6 introns in the oyster $h s c 70$ (Boutet et al., 2003). The number of 
intron in $h s c 70$ seems conserved in vertebrates but variable in invertebrates.

Heat shock element (HSE) is an important element in the promoter region of a heat shock protein gene. When cells receive heat or stress stimulation, activated heat shock factors will bind to the HSEs then rapidly start the transcription (Perisic et al., 1989; Sorger and Nelson, 1989; Westwood et al., 1991; Pirkkala et al., 2001). There is no canonical correlative rule between the number of HSE and the degree of induced expression by a heat shock. But more or less, increasing the number of HSE could enhance the expression of the heat shock protein (Amin et al., 1987; Brade et al., 2000). Only one perfect HSE was predicted in the upstream sequence of the tiger shrimp hsc70 (Fig. 2). This may explain why the tiger shrimp HSC70 expression can not be induced by higher-fold.

There are several predicted CAAT boxes in the upstream sequence of the tiger shrimp hsc70 (Fig. 2). CAAT boxes are usually found in $h s c 70$ promoters of human $h s p 70 A$ (Morgan et al., 1987), Xenopus hsp70 (Bienz and Pelham, 1986), and rat constitutively expressed $h s p 70$-like gene (Sorger and Pelham, 1987). Its role in the basic transcription of $h s p 70$ also was verified.

There is a region containing 14 deoxyguanylates (Gs) near before the start codon (ATG) and in the intron (Fig. 3). This kind of poly $\mathrm{G}$ regions were reported to be increasing (Carlini et al., 2002; Demaison et al., 2002) or decreasing (Xu and Goodridge, 1999) the transcription in different species. There is a need to elucidate the effect of the 14 Gs in tiger shrimp.

\subsection{In vitro expression assay of hsc70 promoter}

Because there is no stable shrimp cell line available now, the insect $S f 21$ cell line was used for the promoter assay in this study. We assumed that insect cell line is a good candidate to test shrimp promoter because both insect and shrimp belong to Arthropoda. The activity of the full-length promoter in this study was verified using the fluorescent expression on the transfected cells with promoter-EGFP vector (Fig. 3) and the luciferase activity with promoter-luciferase vector (Fig. 4). Unfortunately, neither EGPF fluorescent expression nor luciferase activity could be observed significant higher after treatment with a heat shock on the cells (data not shown) although the HSC70 mRNA expression was induced after a heat shock by about 8 folds in vivo. It has been mentioned previously that if a transfection processing causes a severe stress on the cells, the induction of HSP70 expression by a heat shock can not be easily detected (Shu et al., 2003). Another possible reason might be due to the heterogeneity of the assay system. The insect $S f 21$ cells could not provide a well-matched heat shock signal to regulate the promoter of the shrimp. An optimum condition for the heat shock induction of the $h s c 70$ promoter in vitro needs to be determined.

\subsection{Serial deletions on the activity of the hsc70 promoter}

In the region of 2644-2161 bp ahead of translation start codon ATG, a SP1, a CCAAT and an imperfect HSE sites were predicted. The deletions of the region could not significantly affect the promoter activity (Fig. 4) suggesting that the distant sites have no effect on the basic transcription of the tiger shrimp hsc70 promoter.

The deletion of 2160-1800 bp ahead of start codon, which removes the predicted GC box, NF-kB and CCAAT sites, decreased the promoter expression to a significantly low level. It indicates that the deleted site has an important role in the basic transcription of the $h s c 70$ promoter among the near GC box, $\mathrm{NF}-\kappa \mathrm{B}$ and CCAAT sites.

The fragment containing only $2644-1780$ bp ahead of start codon ATG without the predicted core promoter region, the perfect HSE and a CAAT box has significantly lower activity than the full-length promoter. It confirmed the essential role of the core promoter region, the perfect HSE and the near CAAT box in the transcription.

\subsection{The hsc70 promoter was regulated by virus infection}

To investigate the effect of virus infection, well-established AcMNPV was used in the infection of the $S f 21$ cells which were transfected with the luciferase reporter gene triggered by the tiger shrimp $h s c 70$ promoter. The heavy infection increased the expression of the luciferase (Fig. 5). In $S f 21$ and TN368 cells, AcMNPV early gene transactivators IE1 and IE2 can stimulate the expression of the promoter from the Drosophila heat shock 70 protein gene (Crouch and Passarelli, 2005). The higher expression of the tiger shrimp hsc70 promoter by the infection could have been caused by a similar regulation.

Regarding the chemical induction, human HSP70 gene can be induced by the amino acid analog azetidine $(5 \mathrm{mM}, 2-16 \mathrm{~h}$ incubation for RNA level) or the heavy metal ion (cadmium sulfate) (Mosser et al., 1988; Williams and Morimoto, 1990). An exposure to $\mathrm{Hg}$ and $\mathrm{Cu}$ induces the expression of HSP70 in freshwater prawn (Yamuna et al., 2000). $\mathrm{CuSO}_{4}, \mathrm{CdCl}_{2}$ or $\mathrm{NaAsO}_{2}(50 \mu \mathrm{M}$ forl h) can cause high HSP70 accumulation in rainbow trout hepatocytes but HSC70 shows no change (Boone and Vijayan, 2002). In the present study, amino acid analogs and arsenic acid were tested on the tiger shrimp $h s c 70$ promoter with the same or higher doses and incubation periods than the previous studies. Either the arsenic acid or amino acid analogs canavanine or azetidine could not affect the activity of the $h s c 70$ promoter using ANOVA $(\alpha=0.05)$ even though some of them seemed to elevate the expression compared with control $(0 \mu \mathrm{M})$ (Figs. 6 and 7). The inducibility of tiger shrimp hsc70 promoter by the amino acid analogs or arsenic acid might be low.

\section{Conclusion}

In this study, the HSC70 mRNA level of tiger shrimp was induced after heat shock treatment. The $h s c 70$ gene structure of tiger shrimp was described. The $5^{\prime}$-flanking region contains the promoter and transcriptional elements. The activity of the promoter was verified in heterogeneous cell culture system and was elevated by virus infection. The effects of serial deletions on the $h s c 70$ promoter were also described; the importance of near predicted elements in the basic transcription was verified. 


\section{Acknowledgements}

Authors would like to thank Prof. Huai-Jen Tsai, Institute of Molecular and Cellular Biology, National Taiwan University, and Dr. Li-Ling Liaw, Bioresources Collection and Research Center, Food Industry Research and Development Institute, for impartation of technique. This work was supported financially by Council of Agriculture, Republic of China with grant no. 94AS-5.1.6-FAF1 and partially supported by Ministry of Education, Republic of China with grant no. 95R0066-BM04-06.

\section{References}

Amin, J., Mestril, R., Schiller, P., Dreano, M., Voellmy, R., 1987. Organization of the Drosophila melanogaster hsp70 heat shock regulation unit. Mol. Cell. Biol. 7, 1055-1062.

Bienz, M., Pelham, H.R., 1986. Heat shock regulatory elements function as an inducible enhancer in the Xenopus hsp70 gene and when linked to a heterologous promoter. Cell 45, 753-760.

Boone, A.N., Vijayan, M.M., 2002. Constitutive heat shock protein 70 (HSC70) expression in rainbow trout hepatocytes: effect of heat shock and heavy metal exposure. Comp. Biochem. Physiol. C, Toxicol. Pharmacol. 132, 223-233.

Boutet, I., Tanguy, A., Rousseau, S., Auffret, M., Moraga, D., 2003. Molecular identification and expression of heat shock cognate 70 (hsc70) and heat shock protein 70 (hsp70) genes in the Pacific oyster Crassostrea gigas. Cell Stress Chaperones 8, 76-85.

Brade, A.N., Ngo, D., Szmitko, P., Li, P.X., Liu, F.F., Klamut, H.J., 2000. Heatdirected gene targeting of adenoviral vectors to tumor cells. Cancer Gene Ther. 7, 1566-1574.

Bukau, B., Deuerling, E., Pfund, C., Craig, E.A., 2000. Getting newly synthesized proteins into shape. Cell 101, 119-122.

Bukau, B., Horwich, A.L., 1998. The Hsp70 and Hsp60 chaperone machines. Cell 92, 351-366.

Carlini, L.E., Getz, M.J., Strauch, A.R., Kelm Jr., R.J., 2002. Cryptic MCAT enhancer regulation in fibroblasts and smooth muscle cells. Suppression of TEF-1 mediated activation by the single-stranded DNA-binding proteins, Pur alpha, Pur beta, and MSY1. J. Biol. Chem. 277, 8682-8692.

Cheng, S.H., So, C.H., Chan, P.K., Cheng, C.W., Wu, R.S., 2003. Cloning of the HSP70 gene in barnacle larvae and its expression under hypoxic conditions. Mar. Pollut. Bull. 46, 665-671.

Crouch, E.A., Passarelli, A.L., 2005. Effects of baculovirus transactivators IE-1 and IE-2 on the Drosophila heat shock 70 promoter in two insect cell lines. Arch. Virol. 150, 1563-1578.

Demaison, C., et al., 2002. High-level transduction and gene expression in hematopoietic repopulating cells using a human immunodeficiency [correction of imunodeficiency] virus type 1-based lentiviral vector containing an internal spleen focus forming virus promoter. Hum. Gene Ther. 13, 803-813.

Dworniczak, B., Mirault, M.E., 1987. Structure and expression of a human-gene coding for a $71 \mathrm{kD}$ heat-shock cognate protein. Nucleic Acids Res. 15, 5181-5197.

Giebel, L.B., Dworniczak, B.P., Bautz, E.K.F., 1988. Developmental regulation of a constitutively expressed mouse messenger-RNA encoding a $72-\mathrm{kDa}$ heat shock-like protein. Dev. Biol. 125, 200-207.

Hartl, F.U., 1996. Molecular chaperones in cellular protein folding. Nature 381, $571-579$.
Kraus, V.B., Moran, E., Nevins, J.R., 1992. Promoter-specific trans-activation by the adenovirus E1A12S product involves separate E1A domains. Mol. Cell Biol. 12, 4391-4399.

Liu, J., Yang, W.J., Zhu, X.J., Karouna-Renier, N.K., Rao, R.K., 2004. Molecular cloning and expression of two HSP70 genes in the prawn, $\mathrm{Ma}$ crobrachium rosenbergii. Cell Stress Chaperones 9, 313-323.

Lo, W.Y., Liu, K.F., Liao, I.C., Song, Y.L., 2004. Cloning and molecular characterization of heat shock cognate 70 from tiger shrimp (Penaeus monodon). Cell Stress Chaperones 9, 332-343.

Morgan, W.D., Williams, G.T., Morimoto, R.I., Greene, J., Kingston, R.E., Tjian, R., 1987. Two transcriptional activators, CCAAT-box-binding transcription factor and heat shock transcription factor, interact with a human hsp70 gene promoter. Mol. Cell Biol. 7, 1129-1138.

Mosser, D.D., Theodorakis, N.G., Morimoto, R.I., 1988. Coordinate changes in heat shock element-binding activity and HSP70 gene transcription rates in human cells. Mol. Cell. Biol. 8, 4736-4744.

Park, J.H., et al., 2001. Genomic cloning of the Hsc71 gene in the hermaphroditic teleost Rivulus marmoratus and analysis of its expression in skeletal muscle: identification of a novel muscle-preferred regulatory element. Nucleic Acids Res. 29, 3041-3050.

Perisic, O., Xiao, H., Lis, J.T., 1989. Stable binding of Drosophila heat shock factor to head-to-head and tail-to-tail repeats of a conserved 5 bp recognition unit. Cell 59, 797-806.

Perkins, L.A., Doctor, J.S., Zhang, K., Stinson, L., Perrimon, N., Craig, E.A., 1990. Molecular and developmental characterization of the heat-shock cognate-4 gene of Drosophila melanogaster. Mol. Cell. Biol. 10, 3232-3238.

Pirkkala, L., Nykanen, P., Sistonen, L., 2001. Roles of the heat shock transcription factors in regulation of the heat shock response and beyond. Faseb J. 15, 1118-1131.

Reese, M.G., 2001. Application of a time-delay neural network to promoter annotation in the Drosophila melanogaster genome. Comput. Chem. 26, 51-56.

Sambrook, J., Russell, D.W., 2001. Preparation and analysis of eukaryotic genomic DNA ‘in' Molecular cloning: a laboratory manual, 3rd ed. Cold Spring Harbor Laboratory Press, Cold Spring Harbor, New York.

Shu, L., Katholi, C.R., Higazi, T., Unnasch, T.R., 2003. Analysis of the Brugia malayi HSP70 promoter using a homologous transient transfection system. Mol. Biochem. Parasitol. 128, 67-75.

Sorger, P.K., Nelson, H.C., 1989. Trimerization of a yeast transcriptional activator via a coiled-coil motif. Cell 59, 807-813.

Sorger, P.K., Pelham, H.R., 1987. Cloning and expression of a gene encoding hsc73, the major hsp70-like protein in unstressed rat cells. Embo J. 6, 993-998.

Spees, J.L., Chang, S.A., Snyder, M.J., Chang, E.S., 2002. Osmotic induction of stress-responsive gene expression in the lobster Homarus americanus. Biol. Bull 203, 331-337.

Westwood, J.T., Clos, J., Wu, C., 1991. Stress-induced oligomerization and chromosomal relocalization of heat-shock factor. Nature 353, 822-827.

Williams, G.T., Morimoto, R.I., 1990. Maximal stress-induced transcription from the human HSP70 promoter requires interactions with the basal promoter elements independent of rotational alignment. Mol. Cell. Biol. 10, 3125-3136.

Xu, G., Goodridge, A.G., 1999. Function of a C-rich sequence in the polypyrimidine/polypurine tract of the promoter of the chicken malic enzyme gene depends on promoter context. Arch. Biochem. Biophys. 363, 202-212.

Yamuna, A., Kabila, V., Geraldine, P., 2000. Expression of heat shock protein 70 in freshwater prawn Macrobrachium malcolmsonii (H. Milne Edwards) following exposure to $\mathrm{Hg}$ and $\mathrm{Cu}$. Indian J. Exp. Biol. 38, 921-925.

Zafarullah, M., Wisniewski, J., Shworak, N.W., Schieman, S., Misra, S., Gedamu, L., 1992. Molecular-cloning and characterization of a constitutively expressed heat-shock-cognate Hsc71-gene from rainbow-trout. Eur. J. Biochem. 204, 893-900. 